DOI: https://doi.org/10.5007/1980-3532.2016n16p73

\title{
Ocupar é resistir: um estudo sobre as ocupações secundaristas do Rio de Janeiro em 2016
}

\author{
Occupy is resist: a study of high school students occupations in \\ Rio de Janeiro in 2016
}

Bruna Amaral Lanzillotti Barreto Universidade Federal Fluminense (UFF)

Graduanda em Ciências Sociais brulanzillotti@gmail.com

\begin{abstract}
Resumo: No primeiro semestre de 2016, mais de setenta escolas da Rede Estadual de Educação foram ocupadas por estudantes no Rio de Janeiro. Gerada por intermédio da produção audiovisual, produzida pelo projeto Ocupa Educação do PIBID, a análise presente neste artigo está centrada em experiências de campo em escolas públicas de Niterói, em um acervo de mais de 10 horas de gravação que produziram material audiovisual sobre o cotidiano das ocupações, os conflitos, as relações pedagógicas e também percepções relatadas pelos estudantes. Os objetivos aqui traçados são pensar sobre algumas políticas neoliberais às quais se contrapõem essas resistências, as particularidades dessas ações em suas relações com os tradicionais movimentos sociais e, ainda, a fertilidade da reflexão sobre esse tema para a compreensão das relações de poder atualmente estabelecidas e repertórios possíveis de resistência abertos a partir desses levantes.
\end{abstract}

Palavras-chave: Ocupações Secundaristas. Resistência. Neoliberalismo. Educação Pública. Movimentos Sociais.

Abstract: In the first quarter of 2016, students in Rio de Janeiro occupied more than 70 state schools. By means of audiovisual production, generated by the project Ocupa Educação realized through PIBID (a governmental program of teacher formation), this study is centered on field experiences in Niterói public schools, in more than 10 hours of recording generated audiovisual material about day-by-day of occupations, the conflicts, the pedagogical relationships and also perceptions reported by students. The objectives of this article are thinking about some liberal policies, which oppose this resistance, the particularities of these actions in its relations with traditional social movements and still, the fertility of the reflection on this theme to the understanding of the power relations currently established and possible repertoire of open resistance from these uprisings.

Keywords: High School occupations. Resistance. Neoliberalism. Brazilian public education. Social movements.

Originais recebidos em: 24/09/2017

Aceito para publicação em: 25/01/2018

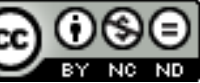

Este trabalho está licenciado sob uma Licença Creative Commons Atribuição-Uso NãoComercial-Vedada a criação de obras derivadas 3.0 Unported License

Revista Em Debate (UFSC), Florianópolis, volume 16, p. 73-94, 2016. ISSNe 1980-3532 


\section{Introdução}

Do final de 2015 até meados de 2016 o Brasil vivenciou mobilizações estudantis massivas nas redes de escolas públicas de Ensino Médio. Após o primeiro epicentro em São Paulo, o terremoto secundarista estremeceu o país na luta contra sucessivos cortes de verbas e privatizações na educação, passando por Goiás, Mato Grosso, Ceará, Rio Grande do Sul e Rio de Janeiro. No Rio, no primeiro semestre de 2016, cerca de 80 escolas foram ocupadas.

Esses processos de ocupação trouxeram novas respostas a problemas recorrentes. A escola é um cenário transpassado por inúmeras problemáticas sociais e, por isso, foram levantadas questões que, para além do campo da Educação, são fundamentais para compreender a sociedade de forma mais ampla. São exemplos os debates acerca das grandes empresas de mídia e a construção de seus discursos hegemônicos; das violências físicas e simbólicas exercidas pelo Estado; do papel e dos posicionamentos do Poder Judiciário; e da organização dos Movimentos Sociais.

Dessas muitas possibilidades, neste artigo, me atenho a reflexão sobre causas político-econômicas estruturais e conjunturais que impulsionaram as ações coletivas dos secundaristas. Também busco analisar questões sobre a organização dos Movimentos Sociais tradicionais em relação a essas formas de mobilização emergentes e algumas de suas características.

Nesse sentido, o primeiro ponto a ser abordando é o tema do Neoliberalismo em algumas de suas faces: ações político-econômicas e lógicas de construção de sujeitos discutindo, respectivamente, políticas com esse viés implantadas na educação brasileira em tempos recentes e a definição de Foucault do conceito de Neoliberalismo, presente no Nascimento da Biopolítica ((FOUCAULT, 2008).

O segundo momento do texto é dedicado à conjuntura político-econômica e de mobilizações no campo da Educação Pública do Rio de Janeiro no início de 2016 e a inserção em campo por meio das técnicas da Antropologia Visual em ocupações na cidade de Niterói, onde e quando, através do Projeto Ocupa Educação, articulado pelo PIBID (Programa de Bolsa de Iniciação à Docência) em parceria com o Laboratório do Filme Etnográfico da Universidade Federal Fluminense (LAB), se originou a pesquisa que fundamenta este artigo.

Por fim, há um levantamento das características políticas e organizacionais das 
ocupações, pensadas à luz do debate realizado por Marília Sposito no texto Ação coletiva, jovens e engajamento militante (2014), onde, fundamentada em reflexões de Lefebvre e Melucci, a autora pensa as mobilizações sociais contemporâneas pela categoria “Ação coletiva” em relação aos Movimentos Sociais tradicionais.

\section{As faces neoliberais na educação}

Privatizações, flexibilização das relações trabalhistas e cortes de gastos públicos nos setores sociais se expandiram no Brasil desde pelos menos os anos 90. Com o cenário de crise econômica mundial a partir de 2008, a agenda neoliberal tem sido apontada como a saída para os problemas econômicos, embora constantemente em oposição a demandas sociais. Nesse sentido, para compreender as mobilizações secundaristas, é fundamental apresentar o que entendo, aqui, enquanto Neoliberalismo.

Para tal, recorro a duas aulas de Michel Foucault presentes no livro $O$ Nascimento da Biopolítica onde o autor expõe uma trajetória histórica e teórica do pensamento neoliberal em seus principais expoentes, focando especificamente na reflexão sobre o neoliberalismo alemão, que indica ser, por suas características, a forma geral do neoliberalismo contemporâneo (FOUCAULT, 2008, p. 179).

No pensamento neoliberal "[...] o mercado é um regulador econômico e social geral, o que não quer dizer, entretanto, que ele é um dado natural [...]. [Se trata de] uma espécie de mecanismo sutil muito seguro, mas só se funcionar bem e se nada vier perturbá-lo" (id, p. 192). Nesse sentido, para os neoliberais, os governos devem ser intervencionistas, ao contrário do que usualmente se aponta, resguardando, porém, a especificidade do como intervir (id, p. 184). $O$ alvo principal das ações governamentais não deve ser objetivamente o mercado - no qual deve interferir quando conjunturalmente necessário, mas suas condições de existência. Nesses moldes, o Estado atua com foco na população para adequá-la à economia de mercado, permitindo o pleno funcionamento do mesmo.

\footnotetext{
"Ora, em relação a essa sociedade que se tornou [com a ascensão do neoliberalismo] [...] o próprio objeto da intervenção governamental, da prática governamental, o que [...] [esse tipo de governo] quer fazer? Ele quer fazer, é claro, que o mercado seja possível. Tem de ser possível se se quiser que desempenhe seu papel de regulador geral, de princípio da racionalidade politica. [...] Vale dizer que o que se procura obter não é uma sociedade submetida ao efeito-mercadoria, é uma sociedade submetida à dinâmica concorrencial. Não uma sociedade de supermercado - uma sociedade empresarial. O homo oeconomicus que se quer reconstruir não é o homem da
} 
troca, não é homem consumidor, é o homem da empresa e da produção." (FOUCAULT, 2008, p. 200-201).

Afirmando a pertinência dessas definições para compreender as ações de governo que se acentuam cada vez mais no Brasil, é interessante refletir a partir das formas de intervenção neoliberais explicadas por Foucault: por um lado, o perfil de intervenção conjuntural, diretamente no mercado - as ações reguladoras definidas pelo pensador neoliberal Eucken (id, p.191.). Por outro, o que os neoliberais chamam de "moldura", que são intervenções que buscam moldar a sociedade de acordo com o mercado.

Dois momentos da relação entre o Brasil e o Fundo Monetário Internacional (FMI), um dos principais agentes globais da difusão das concepções neoliberais de governo, elucidam bem o que seriam as ações reguladoras mencionadas. O FMI realiza avaliações das economias nacionais de seus membros e prescreve políticas econômicas a serem implantadas por eles, indicando, por exemplo, direcionamentos para a organização dos orçamentos públicos. Isso pode ser observado tanto quando se pensa os anos 90, quanto refletindo sobre 2017, conforme os exemplos a seguir.

Segundo informações da publicação da Campanha Nacional pelo Direito à Educação, "O Impacto do FMI na Educação Brasileira” (1999), o Brasil participou de um acordo com o fundo para o recebimento de um empréstimo onde firmava como compromisso central elevar suas receitas e cortar os gastos para garantir o superávit primário. Na prática, o orçamento de 1999 sofreu cortes centralmente nos setores sociais como em saúde, educação e proteção social - nada diferente do que se observa atualmente. No relatório Article IV Consultation (FMI, 2017), feito pelo FMI para o Brasil e publicado em junho de 2017, é afirmado que para superar a atual recessão econômica e restaurar a sustentabilidade fiscal do país são necessárias medidas como o estabelecimento do teto dos gastos públicos, já feito através da Emenda Constitucional 95, e as reformas na seguridade social, como a Reforma da Previdência, atualmente em discussão, ambas as ações com foco na garantia do superávit primário.

Em ambas as situações descritas, observamos intervenções conjunturais do poder para manter o funcionamento do mercado em moldes considerados adequados de acordo com a percepção neoliberal. Há, por outro lado, a chave das intervenções de caráter estrutural, que visam moldar a população, os sujeitos. Para exemplificá-las cabe o caso do Ministério da Educação (MEC). Seu Planejamento Estratégico Institucional 
2015 - 2018 (MEC, 2015) demostra a organização empresarial adotada com o trabalho pautado em métodos como "Cadeia de Valor - ferramenta de gestão que representa o conjunto de processos de uma organização e os valores gerados" (id. p. 8). Ao longo de todo o documento, é demonstrado o perfil neoliberal da organização. Por exemplo, nos objetivos traçados nesse documento para o cumprimento das Metas do Plano Nacional de Educação, todas são mensuradas a partir de dados estatísticos e indicadores quantitativos como os percentuais da população que frequentam determinado nível de ensino ou os resultados de avaliações como a Avaliação Nacional da Alfabetização (ANA) e o Índice de Desenvolvimento da Educação Básica (IDEB). Ainda nesse documento, um ponto demonstra a presença de um projeto de organização da sociedade que objetiva o funcionamento do mercado: o resultado final esperado com a conclusão da Educação Básica é o cidadão em condições de ingressar no mercado de trabalho.

O exemplo do MEC aponta para a condução da Educação pública brasileira segundo o modelo neoliberal de gestão e objetivos. Essa situação se replica nos estados, que é o nível de gestão responsável pelas escolas da Educação Básica, onde ocorreram as ocupações. Conforme apontado por Brenner e Carrano (2014), são essas redes que sofreram nos últimos anos o maior avanço no número de matrículas, principalmente na ampliação do público jovem das camadas populares.

As redes públicas estaduais, além de infladas de estudantes, são precarizadas estrutural e pedagogicamente em consequência de políticas como as mencionadas. Faltam professores e material, escolas são fechadas, as avaliações de desempenho são massivas e não captam as questões pedagógicas densas da vida escolar e a organização do ensino é voltada para formação de mão de obra.

A aplicação dessas políticas de governo não acontece, entretanto, sem a resistência dos setores sociais politicamente organizados. Greves, manifestações, processos, abaixo-assinados, petições públicas, articulações entre lideranças, disputas eleitorais.... Um vasto repertório político vem sendo acionado na luta em oposição ao Neoliberalismo e, a partir do final de 2015, as ocupações de escolas por estudantes secundaristas entraram em cena, a partir das fortes mobilizações dos jovens de São Paulo, como uma nova possibilidade de ação coletiva em espaços que não eram usualmente ocupados para esse fim, fazendo emergir não apenas as ocupações como tática eficaz, mas também, com sua forma específica de organização cotidiana levantou elementos fundamentais para a reflexão acerca desses novos movimentos. 
No início de 2016 Goiás teve ocupações em cerca de 28 escolas. No Ceará, chegam a ser contabilizadas 69. Mais 15 ocupações de escola, além de instituições como secretarias e diretorias regionais de ensino e prédios administrativos de São Paulo. No Rio de Janeiro foram cerca de 80, no Rio Grande do Sul 150 e no Mato Grosso mais de 20 colégios estaduais ocupados.

Em todas essas mobilizações se repetiram demandas em relação ao fim da precariedade da estrutura física das escolas, e dos cortes nas já escassas verbas para a educação. Havia também reivindicações contra formas de privatização dos sistemas de ensino, como em Goiás, com o projeto de transferência da gestão das escolas para Organizações Sociais - instituições de caráter privado. Também a questão da oposição à militarização do ensino nesse mesmo estado e a presença da Polícia Militar nos colégios no Rio foram pautas. São Paulo e Goiás tiveram com muita força a marca da repressão policial para realizar desocupações. Ainda as ocupações de órgãos como regionais de educação foram muito fortes em São Paulo, mas ocorreram também no Rio de Janeiro e em Goiás.

\section{Conjuntura da educação pública no Rio de Janeiro e as ocupações}

No final do segundo bimestre de 2016, o cenário de crise se intensificou no Rio de Janeiro e aumentaram, então, os cortes de gastos sociais, ajustes físcais e atrasos nos salários dos servidores públicos, repercutindo diretamente no cotidiano da Rede Pública de Educação. Nesse contexto, os professores estavam com salários atrasados e o Sindicato dos Professores da Rede Estadual do Rio de Janeiro (SEPE-RJ) iniciou uma Greve. O projeto de formação docente ${ }^{1}$ nas escolas, do qual eu participava, pareceu, então, estar suspenso. Entretanto, essa inércia se altera completamente quando, em 21 de março de 2016, foi ocupada a primeira escola no Rio, o Colégio Estadual Prefeito Mendes de Moraes.

Os estudantes elencaram, em seu manifesto publicado na página da \#OcupaMendes no Facebook, diversas pautas com caráter pedagógico, político e estrutural, pertinentes à toda a rede. A exemplo da \#OcupaMendes, inúmeros colégios foram encorpando essa mobilização, fundamentalmente na área metropolitana; foram cerca de 80 instituições no auge do movimento, além de duas ocupações na Secretaria

\footnotetext{
${ }^{1}$ PIBID - Programa Institucional de Bolsa de Iniciação à Docência.

Revista Em Debate (UFSC), Florianópolis, volume 16, p. 73-94, 2016. ISSNe 1980-3532
} 
de Estado de Educação (SEEDUC) feitas por grupos de diversas escolas.

Essas dezenas de ocupações receberam apoio de diversos grupos, como pais, professores, universitários, mídia independente, artistas, ex-alunos. Enfrentaram, muitas vezes, oposição das direções escolares, alinhadas à Secretaria de Educação (SEEDUC) e de estudantes contrários - os "Desocupa". Relacionaram-se com diversas instituições como a Polícia Militar, o Conselho Tutelar, a Secretaria de Educação, as promotorias do Ministério Público. Foram alvo de avaliações diversas, tanto positivas quanto negativas. Também classificados e analisados pelas grandes empresas de mídia.

Em Niterói foram cinco escolas ocupadas. O Instituto de Educação Professor Ismael Coutinho (IEPIC), localizado no bairro de São Domingos, foi o primeiro na cidade, no dia 07 de abril. No bairro do Badu, o Colégio Estadual Paulo Assis Ribeiro (CEPAR) foi ocupado em 13 de abril. Além desses, o Colégio Estadual David Capistrano (CEDC), localizado em Santa Bárbara, foi ocupado no dia 12 de abril. Mais à frente, em 10 de maio, o Colégio Estadual Pinto Lima (CEPLIM) localizado no centro da cidade, incorporou, também, o movimento, nesse mesmo dia houve ainda a ocupação do Colégio Estadual Leopoldo Fróes (CELF), no bairro do Largo da Batalha. Os estudantes das ocupações não eram somente os ligados a cada uma das escolas onde estavam matriculados, circulavam pelas ocupações jovens de outras escolas, ocupadas ou não, e não apenas da cidade de Niterói.

Esses jovens que já se mobilizavam, há cerca de um mês, em atos de rua em defesa da educação, se identificavam enquanto Secundaristas em Luta - grupo articulado por esses estudantes para organizar, através de assembleias e reuniões, suas ações. Uma característica fundamental do grupo era o fato de serem uma articulação alternativa, independente das entidades burocráticas de organização estudantil, como a UBES e a $\mathrm{UNE}^{2}$, que poderia ser identificada em sua articulação entre os estudantes, através da pauta comum, pelo mencionado uso de uma mesma simbologia em seus nomes, feitos com a hashtag \#Ocupa junto ao nome da escola, pela troca de práticas e pela auto-identificação enquanto parte de um mesmo movimento.

Os Secundaristas em Luta não estavam limitados a essas escolas de Niteroi, mantendo contato com outras escolas, como por exemplo o CIEP 114, Maria Gavazio Martins, em São João de Meriti, município da Baixada Fluminense e o Colégio Estadual

\footnotetext{
${ }^{2}$ União Brasileira dos Estudantes Secundaristas e União Nacional dos Estudantes, respectivamente. Ambas, na época, geridas pela UJS (União da Juventude Socialista) braço jovem do PCdoB (Partido Comunista do Brasil), aliado, na última década, ao PT (Partido dos Trabalhadores).
}

Revista Em Debate (UFSC), Florianópolis, volume 16, p. 73-94, 2016. ISSNe 1980-3532 
Pandiá Calógeras, em São Gonçalo, município da região metropolitana que faz fronteira com Niterói. Antes da primeira ocupação em Niterói há pelo menos 9 registros de passeatas e mobilizações do grupo, conforme acompanhamento do Centro de Mídia Independente $(\mathrm{CMI})$, organização de midiativistas que teve presença constante nas ocupações da cidade. O CMI era considerado pelos estudantes uma fonte confiável acerca de suas ações, visto que eles não permitiam a presença de grupos de mídia hegemônica em seus espaços.

No intuito de se aproximar desse movimento, em meados de abril, a professora Renata Gonçalves, coordenadora do PIBID de Ciências Sociais do qual eu fazia parte, convocou uma reunião com todos seus bolsistas do programa para organizar a atuação do PIBID junto à essas ocupações. Aliando as atividades ao trabalho do Laboratório do Filme Etnográfico (LAB), também coordenado por ela no período, foi introduzido um novo elemento na experiência com a escola: o audiovisual. Nessa reunião se desenhou o esboço de um projeto que uniu uma riqueza de elementos: o audiovisual, a aproximação com novas escolas, o diálogo com os jovens em um espaço ressignificado e a vivência da greve - experiência da docência em seus conflitos sociais. Tudo isso em meio a uma interdisciplinaridade e multiplicidade de abordagens como as do Cinema, da Educação, do Jornalismo e das Ciências Sociais - deram fruto a uma série de atividades e construções coletivas que chamamos de Projeto Ocupa Educação.

A ideia foi visitar as escolas com o equipamento de filmagem e fotografia explicando aos ocupantes nossas características enquanto grupo que se interessava na experiência de estar no espaço ocupado pelas trocas propiciadas nesse convívio. Também com o objetivo de registrar a organização dos estudantes a partir dos seus depoimentos sobre si em filmagens que poderiam servir como divulgação, material de pesquisa e registro de memória.

As inserções se deram em três ocupações: no IEPIC - Instituto de Educação Professor Ismael Coutinho; no CEPLIM - Colégio Estadual Pinto Lima; e no CEPAR Colégio Estadual Paulo Assis Ribeiro. Aconteceram cerca de 15 encontros com esses grupos em campo, ora em ações organizadas pelas ocupações - como atividades pedagógicas, assembleias, reuniões, debates, atos públicos e manifestações; ora pelo PIBID - como o seminário Linhas, Pontos e Nós, na UFF, quando estreou o Documentário do Projeto Ocupa Educação sobre as ocupações e a ida ao Armazém da Utopia para assistir ao espetáculo Sacco e Vanzetti da companhia de Teatro Espaço 
Aberto.

O estudo que dá origem a esse artigo agregou essas experiências de campo a pesquisas em redes sociais, fontes acadêmicas e jornalísticas. Entretanto, o suporte principal do estudo desenvolvido foi o material audiovisual produzido em campo. Por sua especificidade, ele me permitiu, mergulhar novamente naquela realidade com maior qualidade para reanalisar, rememorar, compreender melhor o observado.

Essa percepção das possibilidades trazidas à pesquisa por esse tipo de material é citada por Ana Lúcia Ferraz, fundadora do Laboratório do Filme Etnográfico da UFF, em texto a respeito da Antropologia Visual:

\begin{abstract}
"As técnicas de antropologia visual dinamizam o processo de coleta de dados, abrindo novas facetas no trabalho de análise e interpretação até então limitados à memória do pesquisador e, frequentemente, ao seu gravador de áudio. Acrescente-se a isso a perspectiva de interação sujeito-objeto que essas técnicas proporcionam, permitindo uma maior comunicação com as populações pesquisadas e a possibilidade de levar os resultados das pesquisas a um público mais amplo.” (FERRAZ, 2014, p. 47).
\end{abstract}

Foram produzidas aproximadamente 12 horas de gravação, conforme descrito na tabela 1 .

Tabela 1: Acervo audiovisual das ocupações estudantis na rede estadual em 2016.

\begin{tabular}{llll}
\hline Local & Data de gravação & $\begin{array}{c}\text { Quantidade } \\
\text { de Arquivos }\end{array}$ & Duração (horas) \\
\hline \#OcupaIEPIC & $19 / 04 / 2016$ (terça) & 48 & $01: 49$ \\
\#OcupaIEPIC & 26/04/2016 (terça) & 57 & $02: 59$ \\
\#OcupaCEPAR & $27 / 04 / 2016$ (quarta) & 49 & $01: 30$ \\
\#OcupaIEPIC & 29/04/2016 (sexta) & 9 & $00: 53$ \\
\#OcupaCEPAR & 05/05/2016 (quinta) & 92 & $02: 42$ \\
Ato no Centro do Niterói & 09/05/2016 (segunda) & 91 & $01: 34$ \\
\#OcupaCEPLIM & 25/05/2016 (quarta) & 39 & $01: 04$ \\
Total & $\mathbf{7 ~ d i a s ~}$ & $\mathbf{3 8 5}$ & $\mathbf{1 2 : 3 4}$ \\
\hline
\end{tabular}

Fonte: Elaboração própria.

O dia 19/04/2016 foi a primeira ida à ocupação do IEPIC. Nesse dia, houve uma visita guiada na ocupação feita pelos estudantes, que mostraram como estavam se organizando no espaço, as novas atividades que estavam realizando durante a ocupação. Há depoimentos sobre a forma como começou a ocupação, das impressões dos estudantes sobre o movimento, conversas entre os que estão ocupando e os que não estão. No dia 26/04/2016 é registrado um cine debate sobre as ocupações de estudantes de São Paulo em 2015, realizado também na \#OcupaIEPIC. Há também entrevistas com Revista Em Debate (UFSC), Florianópolis, volume 16, p. 73-94, 2016. ISSNe 1980-3532 
professores que participaram da atividade, e mais depoimentos e uma visita pelo espaço ocupado.

No dia 27/04/2016, houve a visita à \#OcupaCEPAR, onde foram registrados momentos do cotidiano da ocupação, como os alunos praticando esportes e socializando entre si, foi feita uma visita guiada por estudantes pelas dependências da escola e entrevistas com professores e um grupo de estudantes. Nesse mesmo dia houve na escola uma assembleia dos Secundaristas em Luta na qual estudantes de diversas escolas organizaram a forma como seria realizado um ato público para divulgar o movimento de ocupação de escolas. Também registramos no final desse dia uma reunião entre estudantes e pais para falar sobre a \#OcupaCEPAR e a ida dos participantes dessa reunião à outra, em uma igreja evangélica do bairro, essa organizada, por sua vez, pela diretora da escola que convocou responsáveis dos estudantes no intuito de mobilizá-los contra a ocupação.

No dia 29/04/2016, ocorreu o registro de uma reunião com estudantes ocupantes das escolas, representantes da SEEDUC e da Promotoria Pública na \#OcupaIEPIC. Era uma segunda reunião com essas instituições e teve como pauta a questão do RioCard dos estudantes ${ }^{3}$, naquele momento, bloqueado.

Em 05/05/2016, foram registradas diversas atividades na \#OcupaCEPAR. Além de novas visitas às dependências da escola, foi registrado um intenso conflito entre o movimento organizado de desocupação da escola, composto por cerca de 20 estudantes, um pai de aluno e um pastor da região próxima da escola que foram à escola para desocupá-la. Foi registrada uma parte do conflito na porta da escola com as palavras de ordem, cartazes e discussões. Também alguns depoimentos de professores e estudantes de ambos os grupos, além do diálogo final que ocorre entre jovens favoráveis e contrários à ocupação registrado por eles próprios.

No dia 09/05/2016, registramos o ato que havia sido organizado na assembleia do dia 27/04. Participaram dele, além de diversos estudantes das escolas que estavam inseridas nas atividades dos Secundaristas em Luta, estudantes universitários, professores, midiativistas e apoiadores em geral. Acompanhamos desde preparativos feitos na \#OcupaIEPIC, como cartazes, bandeiras e faixas, até o fim do ato, em frente ao terminal rodoviário no centro da cidade.

Por fim, no dia 25/05/2016, foi registrada uma atividade na \#OcupaCEPLIM que

\footnotetext{
${ }^{3}$ Cartão que dá acesso à gratuidade do transporte público no Estado do Rio.

Revista Em Debate (UFSC), Florianópolis, volume 16, p. 73-94, 2016. ISSNe 1980-3532
} 
reuniu estudantes da disciplina de Antropologia e Educação, ministrada pela professora Renata Gonçalves. Nesse dia, houve uma roda de conversa entre os ocupantes da escola e universitários. Havia também a mãe de algumas alunas e um ex-aluno que estava participando da ocupação. Foi feita nesse dia uma visita guiada com o grupo pela escola ocupada. terminal rodoviário no centro da cidade.

Além do registro de debates e do cotidiano das atividades e ações dentro e fora das escolas, há, nesse material, ao menos 35 pessoas entrevistadas ou dando depoimentos específicos para a produção dos vídeos. São principalmente estudantes, mas também professores e pais dos alunos que relatam de forma mais pormenorizada suas percepções e avaliações acerca do movimento, as relações lá estabelecidas, as motivações que os levaram a ocupar ou visitar e apoiar as ocupações, as diferenças entre o ambiente antes e depois, também leituras sobre o posicionamento das mobilizações diante do cenário político de forma mais ampla.

Havia, sobre as filmagens que produzíamos, algumas demandas oriundas dos próprios estudantes das ocupações: o registro do que acontecia era, por um lado, uma defesa, uma prova a respeito de como se davam tanto o cotidiano quanto os conflitos no espaço ocupado. Em casos onde havia a presença dos movimentos de desocupação, por exemplo, a presença daqueles que poderiam registrar os acontecimentos, como de grupos de mídia alternativa e nosso projeto era importante. De outro ângulo, era também uma maneira de divulgar o movimento a outros estudantes e apoiadores, um canal para ampliar suas vozes em outros espaços. Frente a essas demandas, montamos um pequeno filme acerca dessas escolas ocupadas para exibir no seminário Pontos, Linhas e Nós, do NARUA - Núcleo de Antropologia as Artes, Rituais e Sociabilidades Urbanas, que ocorreu no dia 29 de junho de $2016^{4}$.

Já no início de 2017, organizando todo esse material, revi todos os vídeos do acervo. Para cada vídeo assistido, eu descrevi o conteúdo que compreendi como pertinente para a pesquisa, como a transcrição de algumas falas, palavras de ordem, conteúdo dos cartazes produzidos, as situações que ocorriam nas cenas filmadas, ou mesmo as relações com temas pertinentes ao contexto social, conflitos com a estrutura escolar, relações entre os estudantes, relações com o espaço escolar, ações realizadas nas mobilizações de rua, temas debatidos nas assembleias e reuniões.

\footnotetext{
${ }^{4}$ Disponível em: < http://www.labfilmeetnografico.uff.br/producao/filmes/2016/55-ocupa-educacao >. Revista Em Debate (UFSC), Florianópolis, volume 16, p. 73-94, 2016. ISSNe 1980-3532
} 


\section{O Perfil dos Ocupantes}

O perfil social é um fator relevante para compreender quem são esses atores políticos. Por se tratarem de escolas estaduais, concentraram, no geral, um público jovem das camadas populares. Entretanto, cada escola apresentava suas especificidades de acordo com o bairro onde se localizava, a facilidade de acesso a ele, sua maior ou menos proximidade de áreas com intensa violência urbana, o tipo de ensino que oferecia (ensino médio, regular, técnico, educação de jovens e adultos) e o próprio perfil de renda dos jovens que frequentavam a unidade. Dentre os estudantes que organizaram as ocupações, houve ainda um expressivo protagonismo de negros e negras, mulheres e LGBTT's, não apenas tendo papel central nessas ações, mas também pela presença forte de suas pautas nas demandas do movimento.

Outro ponto relevante é o fato de que a grande maioria desses estudantes tinha entre 14 e 18 anos de idade, sendo incluídos na categoria jovem-adolescente, conforme definido pela PEC da Juventude em 2010 (BRENNER e CARRANO, 2014, p. 1225). Algumas questões envolvendo essa a noção de juventude se destacaram nas falas dos estudantes e daqueles que se relacionaram com as ocupações, como pais e professores, e também em um imaginário geral acerca dos ocupas.

Juarez Dayrell, em seu artigo intitulado "O jovem como sujeito social” (2003) fala da necessidade de compreender a juventude como uma categoria que não se explica apenas por sua condição temporal - a faixa etária que se convenciona juridicamente denominar como juventude. Também não somente pela questão biológica - a adolescência, início da juventude, época marcada por mudanças corporais e mentais. A juventude, segundo Dayrell, é vivenciada de acordo com o grupo social do qual esse indivíduo faz parte: se ele vem de uma região periférica ou não, qual seu gênero, de qual grupo étnico faz parte, sua condição de renda, o que ele vivencia em seu cotidiano, ou seja: se trata de uma categoria que varia de acordo com questões culturais, sociais. Nesse sentido, o autor defende não falar em juventude, mas em juventudes. Não limitando, portanto, o significado do ser jovem apenas a condições de certa maneira fixas, como biológica, psicológica e administrativamente, mas afirmando com o plural a diversidade dessa categoria.

\section{Espaços de diálogo, debate e decisão}


Conforme relatavam, em seu cotidiano, os ocupantes das escolas se organizaram através de comissões para a divisão de tarefas. Esses espaços eram rotativos entre eles, podendo o estudante que em um momento estava trabalhando na cozinha ou na limpeza, em outro fazer parte das atividades de comunicação, indo a reuniões e assembleias em outras escolas. Nesse sentido, para além de pautas acerca da necessidade de uma gestão democrática nas escolas, em suas práticas cotidianas, os estudantes realizaram aquilo que reivindicavam.

Uma assembleia dos Secundaristas em Luta no realizada CEPAR, onde se reuniam estudantes de escolas de São Gonçalo e Niterói exemplifica bem como eram organizados seus espaços de debate e decisão. Naquele dia, mais de 35 estudantes de escolas como o IEPIC, o David Capistrano, o Leopoldo Fróes, o Liceu Nilo Peçanha e o Aurelino Leal estavam reunidos para organizar uma manifestação no centro de Niterói que pudesse dar visibilidade ao movimento de ocupações de escolas. Debateram a necessidade de autorização dos pais, arrecadação de dinheiro para manutenção das ocupações e a importância de mostrar o movimento para a sociedade. A ideia dos estudantes era a construção de um ato começando nas barcas (local de grande fluxo de pessoas, em especial trabalhadores e estudantes) e indo até o Liceu, terminando com um cineclube e levando as cadeiras das escolas, a exemplo do que era feito em 2015, em São Paulo.

Todo esse debate se organizou de forma diferente do que é feito tradicionalmente nos espaços do movimento estudantil, com uma mesa que recebe inscrições e a determinação do tempo que cada um pode falar. Os debates eram organizados conforme os estudantes levantavam as mãos para falar e, assim, escutavam uns aos outros. Observavam e regulavam a prioridade de fala aos que ainda não haviam se expressado. Não vi nenhum registro, nesse dia, de alguma decisão que tenha sido votada. As opiniões, inclusive as mais distintas, eram debatidas até que se chegasse a algum consenso: se deviam ou não interromper o trânsito com o ato, qual rua deveriam seguir, qual seria a postura que encontrariam na polícia.

Esse formato de assembleia estava presente não só na relação entre diferentes escolas, mas também na organização do cotidiano. Uma estudante do CEPLIM relata, por exemplo, que para que se organizassem entre si era necessário muito diálogo, por isso faziam as assembleias para tomar decisões em conjunto. Ela afirma que, assim, 
aprendem democracia: "Lá fora dizem que há democracia, mas é na ocupação que está havendo".

Essa forma de organizar a luta política internamente ao grupo é um dos fatores que diferencia esses secundaristas organizados de grupos políticos que tradicionalmente atuam no movimento estudantil e que, por isso, tiveram seus métodos e intervenções sistematicamente rejeitados desde as ocupações de São Paulo em 2015 até os estudantes de Niterói. Em depoimento, estudantes do David Capistrano, por exemplo, falam que romperam com a $\mathrm{ANEL}^{5}$ por ela ser partidária e se uniram aos Secundaristas em Luta. Ainda na manifestação feita pelos estudantes uma de suas palavras de ordem era a seguinte: "A ANEL acha que me enrola. E o RUA ${ }^{6}$ acha que me enrola. UNE e UJS acham que me enrolam. Se liga governista vê se sai da minha escola".

Essa rejeição, entretanto, não se dirigia a qualquer organização exterior à escola - nesse sentido não se trata de uma postura completamente antipartidária. Havia, por exemplo, militantes comunistas que compunham a organização das ocupações, mas o faziam de maneira orgânica, por serem estudantes da rede pública estadual e por construírem cotidianamente o movimento de ocupações. Havia um caráter, na verdade, apartidário, rechaçando que concepções partidárias definidas de maneira externa ao movimento de ocupações determinassem suas práticas e objetivos. Como efetivamente pode ser notado em entrevistas ou em comunicações de grupos como a UBES, apesar de repelida em muitas ocupações, tais organizações buscavam tomar a liderança e a posição de unificadora do movimento, o que pode ser notado, por exemplo, em entrevistas dadas pela presidente da entidade ${ }^{7}$.

Organizações como a UBES e a UNE reproduziam uma estrutura hierárquica muito semelhante às organizações sindicais e movimentos sociais tradicionais que não diferem em muito da própria organização representativa do Estado. A participação se dá através da representação definida em eleições, onde são escolhidas as diretorias que

\footnotetext{
${ }^{5}$ Assembleia Nacional dos Estudantes - Livre grupo que se propõe a organizar nacionalmente o movimento estudantil, rejeitando a estrutura da UNE e é comumente associado ao PSTU (Partido Socialista dos Trabalhadores Unificado).

${ }^{6}$ RUA é um coletivo de juventude autodenominado anticapitalista, integrante do PSOL (Partido Socialismo e Liberdade).

${ }^{7}$ Entrevistas concedidas por Camila Lanes, presidente da UBES, à Carta Educação, em outubro de 2015 acerca das ocupações em São Paulo e à Revista Nordeste, em novembro de 2016, focado no segundo ciclo de ocupações em diferentes estados do país. Disponíveis respectivamente em: < http://www.cartaeducacao.com.br/entrevistas/reorganizacao-escolar-nossa-unica-resposta-e-ocupar-eresistir/ $\mathrm{e}<\mathrm{http}: / /$ revistanordeste.com.br/noticia/revista-nordeste-entrevista-presidenta-da-ubesqueremos-mudar-a-escola/ >, acessadas em 09/07/2017.
}

Revista Em Debate (UFSC), Florianópolis, volume 16, p. 73-94, 2016. ISSNe 1980-3532 
gestionam as entidades. Concorrem a essas gestões grupos partidários organizados que passam, então, a definir a postura política da instituição e, teoricamente, é essa posição que representa o conjunto dos estudantes.

O processo decisório dos secundaristas se deu de maneira inversa. No centro de seus questionamentos parece estar justamente em questão a crítica às hierarquias. Em seus espaços, representavam a si próprios e lidavam com as instâncias de poder de forma coletiva e não através de representações, como aparece, por exemplo, nos registros da ampla reunião feita com a Promotoria de Justiça de Tutela Coletiva de Proteção à Educação do Ministério Público e a Secretaria de Educação no IEPIC. Quando lidavam com representações o faziam de maneira rotativa, como mencionado acerca das comissões. Suas estruturas de decisões não tinham como terminais as votações, mas, fundamentalmente, o consenso. Apesar de sua articulação enquanto estudantes de todo o estado, sua unificação não se materializava na centralização de decisões ou em uma instituição representativa, mas na identidade comum, na defesa das pautas comuns, no intercâmbio de experiências e nas relações de solidariedade cotidiana.

\section{Mobilizações sociais contemporâneas}

Marília Sposito, no texto "Ação coletiva, jovens e engajamento militante" (2014), pensando acerca de novas abordagens para pensar os movimentos sociais traz elementos relevantes para aqueles que querem estudar ações coletivas organizadas centralmente por jovens engajados em alguma militância. Fundamentada a partir de reflexões de Lefebvre e Melucci, a autora analisa essas mobilizações contemporâneas elencando aos que desejam estudá-las algumas questões fundamentais a serem abordadas.

Há uma diferenciação entre o que seriam movimentos de foco no mundo do trabalho, como sendo formas mais antigas, e os movimentos em rede, atuais, que têm tido como protagonistas os jovens que têm sido "[...] pontas de iceberg a experimentar os dilemas advindos das intensas mudanças observadas nos últimos 40 anos." (MELUCCI apud SPOSITO, 2014, p. 98). Para Melucci, conforme aponta Sposito,

“[...] [A] análise das ações coletivas e dos movimentos sociais, apontava para a emergência de modos diferentes de constituições dessas ações sociais, opondo os movimentos personagem, típicos da sociedade industrial centrada 
no mundo do trabalho, aos movimentos sob a forma de redes que marcariam os conflitos decorrentes da mutação social que trazia para a cena na sociedade planetária o conhecimento e a informação como novas formas de dominação de grupos sobre grupos e sobre indivíduos (Melucci, 1991)." (SPOSITO, 2014, p. 109).

Nessa transição, segundo o texto, há um destaque para o potencial conflituoso do cotidiano. A autora se refere às reflexões de Lefebvre indicando que as análises do autor descortinam outra realidade a ser observada com atenção.

"[...] para além do mundo da fábrica e de suas clássicas formas de luta, [há] a
possibilidade de construção de um campo de relações sociais, que não só
acenam para a repetição, mas para um elenco múltiplo de conflitos sociais e
de novos atores para as lutas, muitos deles silenciados até então, como as
mulheres, os jovens, os moradores das grandes cidades" (SPOSITO, 2014, p.
102).

Contextualizando esse debate, Sposito retoma algumas leituras de autores como Lefebvre e Thompson acerca do pensamento de Marx, autor fundamental na discussão dos movimentos sociais. Segundo ela, essas interpretações do pensamento marxista apontam uma recusa da concepção exclusivamente estrutural da realidade, comumente associada ao pensador alemão. Thompson, por exemplo, em sua critica ao estruturalismo marxista, fala da necessidade de se trocar o determinismo das relações de produção pelas determinações históricas dentro de uma lógica processual (id. p. 99): para o historiador inglês, os indivíduos se tornam sujeitos nas experiências. Lefebvre, em sua leitura das últimas obras de Marx, seu período maduro, indica que a reprodução é também das relações sociais e não apenas das relações de produção.

Nesse sentido, Sposito menciona também Reich, pensador marxista menos conhecido, que teria trazido importantes contribuições a esta discussão em suas obras quando debate, por exemplo, a família burguesa, compreendendo-a não como simples produto, mas como reprodutora central das relações sociais capitalistas (id. p. 101). Essas interpretações, de forma geral, indicam que a reprodução das relações sociais não apenas mantém as já existentes, mas formam novas, sendo necessária a reflexão acerca dessas questões para a compreensão das dinâmicas de transformação social na contemporaneidade: “[...] a ideia de reprodução das relações sociais transformou-se em eixo articulador da busca de um modo de compreensão social que retenha seu caráter dinâmico.”(ib).

Quando Foucault trata da forma neoliberal de governo que busca moldar a população e, por consequência, os indivíduos, para que operem sob a lógica de 
mercado, creio estar envolvida essa discussão acerca da reprodução das relações sociais. Nesse sentido me questiono se, pensando acerca das formas de resistência ao poder indicada pelo autor não poderemos levantar também questões acerca das formas de reprodução social.

Essas escolas mobilizadas reagem, em seu cotidiano, fundamentalmente, contra certas formas hierárquicas, sejam nas pedagogias autoritárias - uma hierarquia presente no saber, seja nos espaços políticos - a hierarquia da gestão das escolas e nos movimentos sociais. A presença dessas hierarquias no cotidiano é o que define quem possui sabedoria e quais são os conhecimentos válidos, ou quem tem o direito de gerir o espaço onde todos convivem. Creio que a manutenção dessas formas hierárquicas é uma maneira de reproduzir a sociedade como tem funcionado hoje.

Dessa forma, romper com o modelo de vida neoliberal precisa perpassar as questões cotidianas, nas quais estão em formação os indivíduos que construíram e que reproduzirão essa sociedade. A escola tem docilizado as pessoas para aceitar o próprio mecanismo que as exclui. Um questionamento, por exemplo: são hoje os estudantes oriundos das escolas públicas estaduais que entram majoritariamente nas universidades públicas através do ENEM? Pois alguns deles foram até a porta das ocupações com cartazes pedindo a desocupação dizendo "O ENEM não espera".

Observa-se, aí, uma lógica meritocrática, valor que tem sido muito difundido principalmente quando se trata de educação. Aos melhores pontuadores do SAERJ, por exemplo, havia prêmios como tablets. A partir dessa ideia crê-se que a conquista, o sucesso escolar, e consequentemente a ascensão social que será conseguida com um diploma são resultado de mérito individual, esquecendo de todo o condicionamento social que está envolvido nesse binômio sucesso e fracasso escolar já debatido por Bourdieu e Champagne no importante texto “Os excluídos do Interior” (2015).

Como argumento central dos autores, é apresentado o binômio fracasso e sucesso escolar. Nele, é apontada uma mudança de discurso sobre os fatores que levam a um ou a outro e a relação dessa mudança com o olhar que têm os estudantes para a instituição; em período anterior à expansão do sistema educacional, causas "naturais" ou individuais, como gosto, dom, eram os determinantes apontados. Há, entretanto, uma mudança no discurso da Pedagogia, mudando o patamar da responsabilidade para coletiva, com classificações como "insuficiências pedagógicas", "obstáculos culturais" - o que não traz consigo uma real explicação. É tratada também a questão da 
escolaridade com objetivo nela mesma: o processo de escolarização não é mais mostrado como uma garantia de elevação de status social - " [...] não bastava ter acesso ao ensino secundário para ter êxito nele, ou ter êxito no ensino secundário para ter acesso às posições sociais que podiam ser alcançadas com os certificados escolares [...]" (BOURDIEU e CHAMPAGNE, 2015, p. 246) - desvalorização dos diplomas; a percepção dessa questão é um fator de descrença ou desilusão dos estudantes com a escola.

No referido texto o autor nos atenta para a mudança da forma de exclusão: a exclusão do processo escolar passa a se dar ao longo do tempo e não mais na entrada na instituição, fazendo com que um grupo massivo de pessoas fique inserido na mesma sem fazer, de fato, parte dela. O conceito de "duplo vínculo" é também apresentado: há um processo de recalcamento da verdadeira posição desses estudantes dentro do espaço escolar, que negam, em muito no prolongamento de sua estadia na instituição, a posição social a si associada apesar da escolarização que promete ascensão; nesse sentido há uma dupla consciência de sua condição, uma baseada no que se percebe no espaço e outra pelo que a instituição afirma sobre o indivíduo. O sucesso escolar é resguardado àqueles que têm capital cultural e podem investi-lo do espaço e momento certo; os bens nascidos das famílias abastadas obtêm a ascensão prometida pelos diplomas, mantêm um status que já tinham.

Sob a perspectiva da análise desses autores, o que muitos creem como promessa da educação - e que analisando propostas como a reforma do ensino médio não chega nem mesmo a ser prometido - não é o que será dado aos estudantes ao fim de sua trajetória escolar. O que está presente nas demandas desses jovens que ocupam as escolas, buscando para elas outros sentidos que não esse. Por um lado, travam essa luta se mobilizando contra macropolíticas e por outro em sua estrutura de construção do cotidiano.

O sucesso do neoliberalismo parece estar justamente nessa questão das individualidades, no fato de ele conseguir criar subjetividades controláveis que se adequam a suas macroestruturas. É mudada toda uma cadeia de ensino com o objetivo de criar como produto dela funcionários mais produtivos - que é o objetivo nítido da reforma do ensino médio - forjando sujeitos que se sujeitam a condições extremamente precárias de trabalho e salários miseráveis, por exemplo. 


\section{É preciso ocupar}

Se, por um lado, o neoliberalismo tem produzido essas subjetividades subordinadas, o engajamento desses jovens nas ocupações forma subjetividades resistentes. Creio que é necessário, nesse sentido, afirmar o caráter pedagógico presente nesse engajamento político dos estudantes secundaristas e os possíveis elementos desses processos que podem ser levados à sala de aula, como o exercício da Imaginação Sociológica, pensado por Mills.

Charles Wright Mills, autor que tem sido fundamental para o ensino de Sociologia, afirma que, em seu cotidiano, homens e mulheres acabam se atendo ao que está ao seu redor, não conectando naturalmente essa realidade a uma reflexão mais ampla, dos processos históricos nos quais estão imersos.

$\mathrm{Na}$ vivência desse processo político os jovens fizeram essas conexões, compreendendo, em seu processo, questões sociais relevantes de seu tempo acerca da sociedade em geral. Fizeram emergir consigo uma gama de conflitos sociais atuais que precisam ser debatidos e analisados de forma ampla, para além das vozes que tradicionalmente ocupam posição privilegiada de definição acerca dos acontecimentos, como a da mídia hegemônica e do discurso oficial do Estado.

Relacionando a conjuntura política internacional e os processos econômicos que compõem a sociedade nos últimos anos às suas ações, estes estudantes fizeram o exercício que Mills denomina como Imaginação Sociológica. Segundo o autor, “[...] é a idéia de que o indivíduo só pode compreender sua própria experiência e avaliar seu próprio destino situando-se dentro de seu período" (MILLS, 2009, p. 84). Compreendendo, assim, quem são as pessoas que vivem em seu período histórico e quais suas trajetórias, como eles próprios produzem e são produtos por seu tempo.

De forma distinta às falsas promessas neoliberais feitas aos estudantes, os jovens que ocuparam as escolas se responsabilizaram pelo espaço em todos os aspectos. Suas comissões davam conta de manter tudo funcionando, da limpeza e alimentação até as atividades pedagógicas, em meio ainda da gestão de conflitos com grupos diversos. Nesse processo, foi visto e afirmado pelos estudantes o próprio amadurecimento, desenvolvimento e autonomia, de reflexões críticas sobre a realidade.

Em interessante, a partir disso, observar algumas elaborações de Foucault acerca das formas como seres humanos tornam-se sujeitos. No texto "O Sujeito e o Poder" 
(1995) o autor aponta como seu tema geral - não o poder, entendido pelo senso comum -, mas, na verdade, o sujeito e as formas como os seres humanos tornam-se sujeitos em nossa cultura. Para o autor três formas de objetivação do ser humano atribuíram à ele essa condição: (1) um campo científico, com investigações como a da linguística que observa o sujeito do discurso e da economia com, por exemplo, o sujeito produtivo, que trabalha; (2) também na perspectiva de olhar a si em relação a outros, como o belo em relação ao feio, o culto ao inculto e (3) individualmente, por exemplo, no caso de estudo do autor, que busca compreender "como os homens aprenderam a se reconhecer como sujeitos de sexualidade" (FOUCAULT, 1995, p. 232).

Para Foucault, os sujeitos humanos são colocados em relações de produção, de significação e de poder. E se a Semiótica e a Linguística permitem a compreensão dos sujeitos nas relações de significação e a Economia e a História nas relações de produção, há uma lacuna para a compreensão dos sujeitos humanos nas relações de poder $(i b)$. Ele sugere, então, que, para tal, é necessário conhecer as condições históricas presentes que queremos investigar, sendo a questão do poder essencialmente ligada a "relação entre a racionalização e os excessos do poder político" (id, p. 233). Mas para compreender essa relação, é fértil observar essa racionalização não como um processo geral, mas “analisá-la como um processo em vários campos, cada um dos quais com uma referência a uma experiência fundamental: loucura, doença, morte, crime, sexualidade etc." ( $i b)$. Para captar essas racionalidades, o autor sugere a tomada de uma perspectiva mais empírica: estudar as formas de resistência às diferentes formas de poder (id, p. 234).

As resistências que Foucault aponta têm, segundo ele, caráter antiautoritário, como a luta contra o "[...] poder dos homens sobre as mulheres [...], da medicina sobre a população, da administração sobre o modo de vida das pessoas.” (id, p. 234). Essas resistências apresentam ainda outras características em comum entre si - que creio que podem ser percebidas também nos processos de ocupação das escolas:

“1) São lutas transversais, isto é não são limitadas a um país. [...] não estão confinadas a uma forma política e econômica particular de governo.

2) O objetivo dessas lutas são os efeitos de poder enquanto tal. Por exemplo, a profissão médica não é criticada essencialmente por ser um empreendimento lucrativo, porém, porque exerce um poder sem controle, sobre os corpos das pessoas, sua saúde, sua vida e morte.

3) São lutas "imediatas" por duas razões. Em tais lutas criticam-se as instâncias de poder que lhes são mais próximas, aquelas que exercem sua ação sobre os indivíduos. Elas não objetivam o "inimigo mor", mas o inimigo 
imediato. Nem esperam encontrar uma solução para seus problemas no futuro (isto é, liberações, revoluções, fim da luta de classe). Em relação a uma escala teórica de explicação ou uma ordem revolucionária que polariza o historiador, são lutas anárquicas. [...]

4) São lutas que questionam o estatuto do indivíduo: por um lado afirmam o direito de ser diferente e enfatizam tudo aquilo que torna os indivíduos verdadeiramente individuais. Por outro lado, atacam tudo aquilo que separa o indivíduo, que quebra sua relação com os outros, fragmenta a vida comunitária $[\ldots]$.

Estas lutas não são exatamente nem a favor nem contra o "indivíduo"; mais que isto, são batalhas contra o "governo da individualização".

5) São uma oposição aos efeitos de poder relacionados ao saber, à competência e à qualificação: lutas contra os privilégios do saber. [...]. O que é questionado é a maneira pela qual o saber circula e funciona, suas relações com o poder. [...].

6) Finalmente, todas estas lutas contemporâneas giram em torno da questão: quem somos nós? Elas são uma recusa a essas abstrações, do estado de violência econômico e ideológico, que ignora quem somos individualmente, e também uma recusa de uma investigação científica ou administrativa que determina quem somos.

Em suma, o principal objetivo destas lutas é atacar, não tanto "tal ou tal" instituição de poder ou grupo ou elite ou classe, mas, antes, uma técnica de poder. "(FOUCAULT, 1995, p. 234-235).

Nesse sentido, entendo que a reflexão sobre as ocupações estudantis secundaristas pode trazer inúmeros elementos para a compreensão das relações de poder e das racionalidades com as quais o poder se faz presente e para a interpretação das estratégias utilizadas para mantê-lo.

\section{Referências}

BARRETO, Bruna Amaral Lanzillotti. \#OCUPATUDO: mobilizações secundaristas e resistências à precarização da educação. Monografia (Bacharelado em Ciências Sociais) - ICHF/UFF, Niterói, 2017.

BOURDIEU, P.; CHAMPAGNE, P. Os excluídos do interior. In: CATANI, A.; NOGUEIRA, M. A. Escritos de Educação. 16ª . ed. Petrópolis: Vozes, 2015. p. 244255.

BRENNER, A. K.; CARRANO, P. Os sentidos da presença dos jovens no Ensino Médio: representações da escola em três filmes de estudantes. Educação e Sociedade, Campinas, 35, n. 129, Outubro - Dezembro 2014. 1223-1240.

AÇÃO EDUCATIVA - ASSESSORIA, PESQUISA E INFORMAÇÃO (Coord.). $O$ impacto do FMI na educação brasileira. São Paulo: Campanha Nacional pelo Direito a Educação, 1999. 38 p. 3 ex. 
CAMPOS, A.; MEDEIROS, J.; RIBEIRO, M. Escolas de Luta. São Paulo: Veneta, 2016.

DAYRELL, J. O jovem como sujeito social. Revista Brasileira de Educação, Rio de Janeiro, Set/Out/Nov/Dez 2003. 40-52.

FERRAZ, A. L. Etnografia em filme e Ensino de Antropologia: apontamentos de sala de aula. In: FERRAZ, A. L.; MENDONÇA, J. M. D. Antropologia Visual: Perspectivas de ensino e pesquisa. Brasília: ABA, 2014. p. 35-49.

FMI - International Monetary Fund. Brazil : 2017 Article IV Consultation-Press Release; Staff Report; and Statement by the Executive Director for Brazil. IMF Country Report, no. 17/215. Washington, D.C. 2017. Disponível em: $<$ https://www.imf.org/en/Publications/CR/Issues/2017/07/13/Brazil-2017-Article-IVConsultation-Press-Release-Staff-Report-and-Statement-by-the-45081 >. Acesso em: 09/12/2017> .

FOUCAULT, M. O Sujeito e o Poder. In: DREYFUS, H.; RABINOW, P. Michel Foucault, uma trajetória filosófica para além do estruturalismo e da hermenêutica. Rio de Janeiro: Forense Universitária, 1995. p. 231-249.

M. Aula de 14 de fevereiro de 1979. In: SENELLART, M. Nascimento da biopolítica: curso dado no College de France (1978-1979). São Paulo: Martins Fontes, 2008. p. 179-219.

M. Aula de 7 de fevereiro de 1979. In: SENELLART, M. Nascimento da biopolítica: curso dado no College de France (1978-1979). São Paulo: Martins Fontes, 2008. p. 139-178.

MEC. Planejamento Estratégico Institucional 2015 - 2018. Ministério da Educação. Brasília, DF. 2015. Disponível em:. Acesso em: 28/05/2017 - 17h50.

MILLS, C. W. A promessa. In: MILLS, C. W. Sobre o artesanato intelectual e outros ensaios. Rio de Janeiro: Jorge Zahar Ed., 2009. p. 81-87.

OCUPA Educação. Produção: Projeto Ocupa Educação. Niterói: Laboratório do Filme Etnográfico - $\quad$ UFF, $2016 . \quad$ Disponível $\quad$ em:< http://www.labfilmeetnografico.uff.br/producao/filmes/2016/55-ocupa-educacao >. Acesso em: 01/07/2016.

SPOSITO, M. P. Ação coletiva, jovens e engajamento militante. In: CARRANO, P.; FÁVERO, O. Narrativas juvenis e espaços públicos: olhares de pesquisas em educação, mídia e ciências sociais. Niterói: UFF, 2014. p. 97-130. 